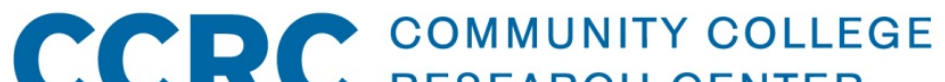 RESEARCH CENTER
}

TEACHERS COLLEGE, COLUMBIA UNIVERSITY

\section{Efficiency in the Community College Sector: Stochastic Frontier Analysis}

\author{
Tommaso Agasisti \\ Politecnico di Milano \\ Clive Belfield \\ Queens College, City University of New York
}

CCRC Working Paper No. 69

March 2014

Address correspondence to:

Clive Belfield

Associate Professor, Economics, Queens College, City University of New York

Research Affiliate, Community College Research Center

Teachers College, Columbia University

525 West 120th Street, Box 174

New York, NY 10027

212-678-3091

Email: belfield@tc.edu

Funding for this study was provided by the Bill \& Melinda Gates Foundation. Author Tommaso Agasisti is grateful to Teachers College, Columbia University, which hosted him during the writing of this paper's first draft (summer 2013), and to the H2CU Center College Italia, which provided him accommodation services during this period. The authors appreciate comments from Davis Jenkins. 


\begin{abstract}
This paper estimates technical efficiency scores across the community college sector. Using stochastic frontier analysis and data from IPEDS for 2003-2010, we estimate efficiency scores for 950 community colleges and perform a series of sensitivity tests to check for robustness. We find that community colleges have become more efficient over time but find no evidence of economies of scale. We also find significant variation in efficiency across colleges, with only part of this variation explained by exogenous differences by state and across student characteristics.
\end{abstract}




\section{Table of Contents}

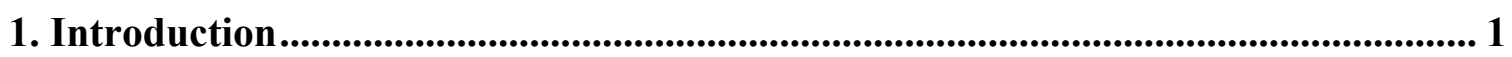

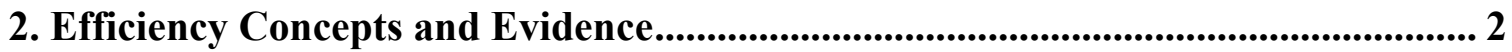

3. Model Specification............................................................................................................ 5

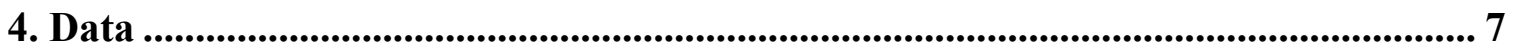

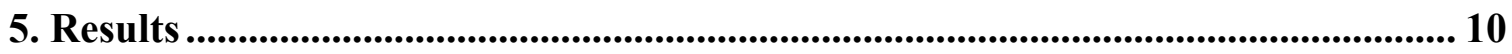

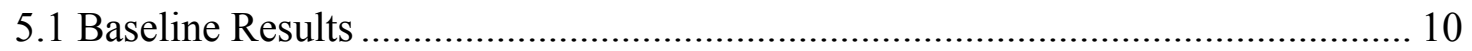

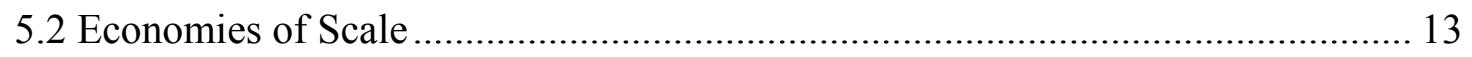

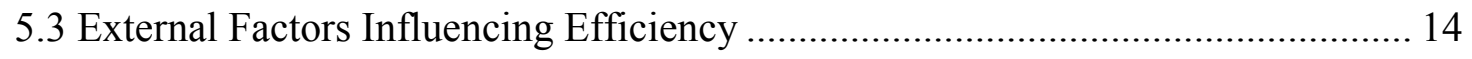

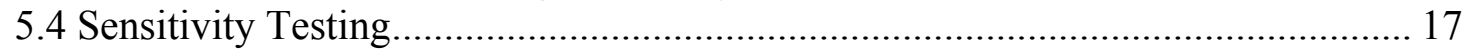

6. Policy Implications...................................................................................................... 20

6.1 Trends in Efficiency Over Time .................................................................... 20

6.2 Ranking Colleges and Resource Implications ............................................. 22

7. Conclusions .................................................................................................................................. 23

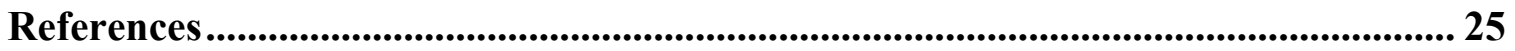

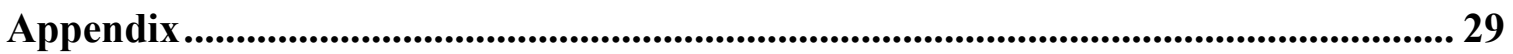





\section{Introduction}

Several recent trends have placed increasing pressure on higher education institutions, including community colleges, to improve performance (National Research Council, 2012). First, rising tuition prices, primarily due to reductions in state subsidies, have prompted debate over college affordability, particularly for low-income students. Second, low absolute graduation rates have provoked questions about whether colleges are delivering enough value for money for the taxpayer. Finally, government agencies have set ambitious goals for increased attainment across higher education and particularly for associate degrees and vocational credentials, which are predominantly awarded by community colleges (Bailey, 2012).

Despite this increased pressure, there has been very little empirical analysis of efficiency in the community college sector (Jenkins \& Rodriguez, 2013; on four-year colleges, see Webber \& Ehrenberg, 2010; Zhang, 2009). The lack of research is surprising because the sector is especially suited for analysis of comparative efficiency: most community colleges are of similar size, offer comparable programs, and, unlike four-year colleges, do not have large research budgets that generate outcomes other than educational attainment. Our analysis aims to fill this gap by estimating college-level technical efficiency over a seven-year period using stochastic frontier analysis. To our knowledge, these estimations are the first to focus specifically on community colleges.

Empirical evidence on efficiency must be integrated into the policy debate. There is considerable evidence that the sector as a whole is allocatively efficient: the economic benefits of college substantially outweigh the costs from the student and taxpayer perspective (Trostel, 2010). However, rather than considering additional investments in postsecondary education, policy is now focused on rating and ranking individual colleges; such ranking systems are intended to help students choose those colleges that deliver the best quality education at the lowest price and so improve technical efficiency across the sector (The White House, Office of the Press Secretary, 2013). From a student perspective, preferred colleges are those that offer high quality education and services relative to the tuition and fees. But from a public perspective, ratings should be based on relative efficiency in the deployment of all resources. Moreover, these ratings should be 
robust to alternative specifications of the rating system and should identify differences in performance that are both consistent over time and substantive (with meaningful resource savings between, for example, the top quartile relative to the bottom quartile of performance).

We estimate college-level technical efficiency to explicitly address these policy issues. With technical efficiency, we specifically refer to the ability of colleges to "transform" their inputs (financial and human resources) into outputs (such as degrees awarded). We begin with a review of efficiency as applied to the community college sector and a summary of evidence. Next, we describe our method of stochastic frontier analysis (SFA) to measure technical efficiency. We then estimate a series of models to identify technical efficiency for each college and to check for model robustness. We use this evidence to address important issues of policy. We conclude with directions for future research.

\section{Efficiency Concepts and Evidence}

Fundamentally, efficiency is the production of a given output at the lowest possible cost. The determination of costs is typically regarded as noncontroversial, but there is considerable conceptual and empirical disagreement on what colleges produce. Colleges produce more than one output and they receive funding from multiple sources, each of which may have a different valuation of output. Often, college personnel equate any reduction in funding with a deterioration in quality and, by implication, output (Powell, Gilleland, \& Pearson, 2012). In addition, there is debate over the extent to which a college is responsible for, or has much control over, its output. Faculty, for example, may be governed by collective bargaining agreements or have guaranteed employment contracts. State-imposed funding formulas restrict how resources can be used. Perhaps most critically, colleges may claim that output is simply a function of student characteristics, aptitudes, and preferences over which they have little control (Winston, 1999). 
Given all these confounding factors, some question whether efficiency and productivity can be determined from such complex enterprises. Colleges, it is claimed, either spend whatever money they have (an assertion noted over three decades ago by Bowen, 1980) or allocate resources based on internal rules and formulas rather than on efficiency considerations. Notwithstanding these concerns, there is still considerable scope for colleges to spend efficiently or wastefully, and all public institutions are facing greater accountability pressures for their use of public funds. By necessity, therefore, it is important to articulate a valid measure of efficiency at the community college level and to empirically identify efficient colleges.

Only two recent studies on community colleges are salient in this regard, and neither is strictly a study about efficiency. Bound, Lovenheim, and Turner (2010) found no link between completion rates and resources (proxied by the student-faculty ratio), and Stange (2012) found no relation between student outcomes and instructional expenditures per student, faculty salaries, or the proportion of faculty who were full-time. One possible interpretation of these studies is that colleges with higher spending are less efficient than colleges with lower spending: they spend more but have the same outcomes. However, an alternative interpretation is that spending on some particular inputs is inefficient or that spending is not the only driver of output. In this case, not only must efficiency be studied, but its determinants should be accounted for-a task specifically undertaken in the present paper. Regardless, neither study allows us to identify the magnitude of efficiency differences across colleges or their ranks. ${ }^{1}$

There is considerable economic research on the efficiency of U.S. four-year colleges (e.g., de Groot, McMahon, \& Volkwein, 1991; Dolan \& Schmidt, 1994; Gainsmeyer-Topf \& Schul, 2006; Harter, Wade, \& Watkins, 2005). Two studies (Cohn, Rhine \& Santos, 1989; Laband \& Lentz, 2004) have pooled two-year and four-year institutions in their analysis, but the results are driven by the latter group. The clearest finding from this research is of economies of scale-larger institutions are more efficient, in that they are able to keep their unit cost lower, all else equal. However, this evidence

\footnotetext{
${ }^{1}$ In related recent research, Clotfelter, Ladd, Muschkin, and Vigdor (2013) have examined institutional variation in degree attainment at community colleges; they found that, once student characteristics are adjusted for, most colleges operate at the same level of performance. Also, Belfield, Crosta, and Jenkins (2013) undertook a detailed investigation of the costs of a cohort of students at a single community college to see how different pathways students take affect efficiency.
} 
has limited applicability for community colleges: the studies typically include variables measuring research expenditures and graduate student enrollments, and they typically exclude from the measure of outputs vocational certificates, which are over 40 percent of all awards conferred by community colleges (Belfield \& Bailey, 2011).

In summary, there is almost no empirical research to properly identify efficiency across community colleges. To address this gap in research, we perform stochastic frontier analysis (SFA) on the sector. As described in the next section, "Model Specification," SFA explicitly assumes that inefficiency affects production, and through frontier techniques it provides estimates of efficiency scores for all the organizations in the industry under consideration (Kumbhakar \& Lovell, 2000).

SFA is common in international literature on technical efficiency in higher education. ${ }^{2}$ (For Italy, Japan, and Germany, see respectively Agasisti \& Johnes, 2010; Hashimoto \& Cohn, 1997; and Kempkes \& Pohl, 2010). These studies suggest substantial differences in institutional performance across colleges (as well, they establish the methodological advantages in using SFA over ordinary least squares [OLS] to estimate cost and production functions). However, the U.S. system is quite distinctive, notably in its reliance on tuition funding and in having large numbers of community colleges that serve older (and relatively disadvantaged) students and that offer associate degrees that may lead to a bachelor's degree. International evidence may thus have limited relevance for the community college sector in the U.S.

Yet, community colleges possess attributes that make them especially suited to comparative efficiency analysis. First, they do not have large research budgets or substantial spending on non-instructional activities (such as research, sports, or medical facilities) which are intended to generate outcomes beyond academic attainment. Second, community colleges do not vary significantly in size (such that technical efficiency cannot be distinguished from scale efficiency), and the sector does not have many outliers (e.g., private, research-intensive elite institutions). Third, students take courses across many departments such that college-level organization matters as much as departmental

\footnotetext{
${ }^{2}$ A parallel literature exists, which uses a non-parametric method called Data Envelopment Analysis (DEA). However, that method does not have the statistic requirements that are necessary for conducting a proper econometric analysis of organizations' performances (see Johnes, 2006, 2008, for discussion on the relative advantages of SFA and DEA).
} 
organization. ${ }^{3}$ Fourth, community colleges operate in local markets but do face competitive pressures as many students have the option of taking introductory courses at a four-year college or enrolling in the for-profit sector. Variations in competition across localities may create different incentives to be efficient. Finally, community college efficiency is unlikely to be dominated by differences in student ability. Many community college students enroll in the college closest to their home, and most colleges (unlike four-year institutions) are not competing in a state or national market for students. Indeed, Stange (2012) found no relationship between student ability and community college quality. Therefore, it is likely that differences in technical efficiency across these colleges should be identifiable using SFA.

\section{Model Specification}

Stochastic frontier analysis can be used to estimate a production function allowing for inefficiency in production (Aigner et al., 1977). The basic SFA form is:

$$
\begin{aligned}
& y_{i}=f\left(X_{i}\right)+\varepsilon_{i} \\
& \varepsilon_{i}=v_{i}-u_{i}
\end{aligned}
$$

where $y_{i}$ is the output produced by community college $i$ and $X_{i}$ is a vector of variables measuring the different inputs employed in production. The error term $\varepsilon_{i}$ is decomposed into $v_{i}$, a random, normally distributed statistical disturbance term, and $u_{i}$, a disturbance term with a one-sided distribution that reflects inefficiency in production (Archibald \& Feldman, 2008a).

With a panel of institutions, an adapted specification is that proposed by Battese and Coelli (1992; hereafter BC-92):

$$
y_{i t}=f\left(X_{i t}\right)+\left(v_{i t}-u_{i t}\right)
$$

where $u_{i t}$ is assumed to follow a truncated normal distribution. The advantage of this specification is that $u$ can vary over time: colleges can experience efficiency gains (or losses) over the period of analysis, and the (restrictive) assumption that efficiency is fixed

\footnotetext{
${ }^{3}$ On adjustments for within-college, departmental heterogeneity, see Agasisti \& Bonomi (2013).
} 
over time can be relaxed. This characteristic of the model is particularly important when the period of time is quite long, as in this paper (seven years).

A baseline specification of the production function includes a measure of cost that captures all the relevant resources and can accommodate fixed effects. The functional form specification has both input(s) and output in logarithms:

$$
\ln \left(y_{i t(s)}\right)=\beta_{0} A+\ln \left(\beta_{1} X_{i t(s)}\right)+\phi_{(s)}+\left(v_{i t}-u_{i t}\right)
$$

where $X_{i t}$ is the cost measure, $\beta_{1}$ is the parameter for cost to be estimated, and $A$ is a constant. Given the many differences in state regulations which affect how community colleges can operate, we include state fixed effects (subscript $s$ ). The parameter $\phi$ represents the effect of the state's structural and regulatory characteristics on productivity: if a college is located in a state where $\phi>0$, then its efficiency estimate without considering the fixed effects is upward biased.

To relax the single-input assumption, a Cobb-Douglas production function specification may be estimated as follows:

$$
\ln \left(y_{i t(s)}\right)=\beta_{0} A+\ln \left(\beta_{1} X_{1 i t(s)}\right)+\ln \left(\beta_{2} X_{2 i t(s)}\right)+\phi_{(s)}+\left(v_{i t}-u_{i t}\right)
$$

where $X_{1}$ is "current expenditures" and $X_{2}$ "other costs", with $\beta_{1}$ and $\beta_{2}$ the parameters to be estimated for the inputs.

Lastly, to identify external factors, which may affect the level of efficiency in the production function, may be specified such that college inefficiency is a function of a set of explanatory variables (Battese \& Coelli, 1995, hereafter BC-95):

$$
\begin{aligned}
& \ln \left(y_{i t}\right)=\beta_{0} A+\ln \left(\beta_{1} X_{i t}\right)+\phi_{(s)}+\left(v_{i t}-u_{i t}\right) \\
& u_{i t}=\delta z_{i t}+W_{i t} \\
& W_{i t} \geq-\delta z_{i t}
\end{aligned}
$$

where $z_{i t}$ is a set of time-varying explanatory variables and $\delta$ are the corresponding parameters to be estimated. $W_{i t}$ is the random variable associated with the estimation of the impact of $z_{i t}$ variables on $u_{i t}$ (following a truncated normal distribution with mean $=0$, variance $=\sigma^{2}$, and truncation point $-\delta z_{i t}$ ). Specification [5] allows for the calculation of "pure efficiency scores" net of the external factors which may be outside the control of the college. These external factors will include the socioeconomic status and age distribution of the student body, intensity of enrollment, and whether the college has a 
vocational mission. Pure efficiency scores are more valid for benchmarking or ranking purposes, as they are not affected by the positive/negative influence of factors, which are beyond the college's control.

The advantages of SFA over using OLS residuals or other unadjusted unit cost statistics are several (see Archibald \& Feldman, 2008). SFA compares colleges with those with similar inputs, adjusting for external characteristics, and compares all colleges

against the most efficient college. Also it imposes a less restrictive functional form on the association between inputs and outputs and so allows for managerial and technical efficiencies to be influential.

\section{Data}

For analysis, we use data on output and costs from IPEDS (the Integrated Postsecondary Education Data System, a system of interrelated surveys conducted by the U.S. Department of Education's National Center for Education Statistics), which yields an unbalanced panel of around 900 community colleges in the period between 2003 and 2010 (Desrochers \& Wellman, 2011). Our output measure reflects both the academic and vocational missions of community colleges and is calculated as the sum of associate degrees and short, medium, and long certificates awarded per year. Across public twoyear colleges, only 56 percent of awards are associate degrees; the remainder are shortterm certificates (23 percent) and moderate or long-term certificates ( 21 percent; see Horn, Li, \& Weko, 2009). Hence, an efficiency study that omits certificates will have substantial measurement error. In this paper, these credentials are weighted by the number of credits required to attain them (with zero weight for remedial credits and for students who do not complete an award). Below, we investigate alternative measures of output; we also investigate different weightings for awards in our sensitivity testing.

One output we are not able to include is the number of students who transfer to four-year colleges. IPEDS does have information on transfer rates from 2003 onward, but their accuracy is questionable; one-quarter of colleges have missing data (Medwick, 
2009). ${ }^{4}$ Also, IPEDS cannot identify if out-transfer students complete awards-fewer than half of all students who transfer ever receive a credential — and it cannot identify if a transfer student goes laterally to another two-year college, of which 40 percent of all transfer students do (Hossler et al., 2012). A further confounding factor is that one-fifth of students transfer out of state, so much transfer may reflect the high mobility rates of young people rather than particular attributes of college operations. However, although many community college students transfer out of their original college, these community colleges also receive transfer students from the four-year system. In fact, community colleges are net recipients of transfer students from four-year colleges (Hossler et al., 2012). Hence, omitting transfer rates may not create significant bias in our analysis.

On the cost side, expenditures are defined as total educational and general expenditures. ${ }^{5}$ We do not subtract student tuition and fees, which are on average 17 percent of college revenues. Therefore, efficiency is viewed from a social perspective rather than a fiscal one (in which high-tuition colleges would be viewed as more efficient, ceteris paribus). We do not include capital expenditures. Although they do not have large endowments or own valuable financial assets, community colleges do vary in age and in the quality of their capital stock. However, available measures of the value of capital stock are very imprecise (in part because of how colleges report replacement values). We adjust all expenditures for state-specific variation in prices (using BLS data) and express in 2010 dollars using the HECA index.

A final caveat is that our measures are annualized. Ideally, outputs should be correlated against college expenditures over the entire period when the students were enrolled: awards given in 2010 reflect resource allocations not just in that year but also in the prior years in which the award-holders were enrolled. This chronic mapping is not feasible because of the heterogeneity in time to completion across subgroups of community college students and insufficient data (Belfield, Crosta, \& Jenkins, 2013). If

\footnotetext{
${ }^{4}$ IPEDS shows a transfer rate of 18 percent for community colleges (Medwick, 2009, Table 9). This is most likely an understatement: a recent National Student Clearinghouse Research Center (Hossler et al., 2012) study calculated the transfer rate using student-level data at 33 percent.

${ }^{5}$ Total education and general expenditures is calculated by summing expenditures on instruction, research, public service, academic support, student services, institutional support, operations and maintenance, and scholarships and fellowships. Other expenditures, including research, are 6 percent of community college expenditures; and 2 percent are defined as public service.
} 
college enrollments and program offerings are stable, however, this measurement error may be small.

Descriptive frequencies for our sample are given in Table 1. Overall, from 2003 to 2010 the (real) average (overall) cost of each college increased from $\$ 36$ million to $\$ 43$ million (+20 percent). However, in the same period, the average level of output increased by 37 percent. While this suggests that efficiency increased over time, it cannot be straightforwardly concluded that the productivity (unit cost) did the same-indeed, average cost/expenditure per student is basically steady. The sector exhibits great heterogeneity (the standard deviation is always greater than the mean). The composition of the student body is stable over time, with the exception of the proportion of young students (which increased in the period from 47 percent to 58 percent).

Table 1

Descriptive Statistics

\begin{tabular}{lrrrrrr} 
& \multicolumn{3}{c}{$\mathbf{2 0 0 3}$} & & \multicolumn{2}{c}{$\mathbf{2 0 1 0}$} \\
\cline { 2 - 6 } & Mean & St. Dev. & $\boldsymbol{N}$ & Mean & St. Dev. & $\boldsymbol{N}$ \\
\hline Output & 595.6 & 788.9 & 968 & 818.9 & 1112.2 & 844 \\
Total Cost (millions) & $\$ 35.6$ & 35.9 & 957 & $\$ 43.2$ & 41.4 & 923 \\
Total Expenditure (millions) & $\$ 27.2$ & 37.5 & 888 & $\$ 31.1$ & 44.1 & 847 \\
Average cost per student & $\$ 71,274$ & 44,880 & 952 & $\$ 71,556$ & 38,028 & 830 \\
Average expenditure per student & $\$ 49,192$ & 39,752 & 883 & $\$ 45,718$ & 38,682 & 795 \\
\hline \% Black students & $13.2 \%$ & & 966 & $14.0 \%$ & & 937 \\
\% Hispanic students & $8.0 \%$ & & 966 & $10.0 \%$ & & 937 \\
\% Part-time students & $55.0 \%$ & & 944 & $53.1 \%$ & & 919 \\
\% Young (< 25 y/o) students & $47.4 \%$ & & 966 & $58.6 \%$ & & 937 \\
\% Vocational colleges & $22.3 \%$ & & 997 & $23.6 \%$ & & 945 \\
\hline Note. IPEDS data. & & & & &
\end{tabular}

Note. IPEDS data. 


\section{Results}

\subsection{Baseline Results}

In the first two columns of Table 2 we report the coefficients of the production function estimated with the baseline log-linear specification with one single input (the Baseline_1 column excludes state-level fixed effects and the Baseline_2 column includes them).

The portion of the overall variance $\left(V_{i}=u_{i}+v_{i}\right)$ that is explained by that of the inefficiency term is 93.7 percent (see gamma, which is $u_{i} / V_{i}$ ), so confirming the presence of inefficiency in production and the necessity to adopt a frontier method to estimate the production function instead of more traditional OLS. The coefficients can be generally intended as elasticities (while the constant can be thought as the fixed cost): an increase of 1 percent in costs is associated with an increase of 0.6 percent in output. Notably, $\eta$, the parameter that measures if efficiency is increasing over time, is statistically significant and positive.

The preferred specification is that shown in the Table 2 Baseline_2 column, as it explicitly assumes structural variation in colleges' efficiency across states. Including state fixed effects does not alter the estimated output elasticity, and the correlation of efficiency scores with and without state fixed effects is $0.792(p<.01)$. However, the average efficiency scores are higher with state fixed effects (see Figure 1): heterogeneity across states is an important driver of efficiency. Figure 1 shows the distributions of efficiency scores for the two baseline models for community colleges in 2010. There is wide variation around the average efficiency score (0.594 for Baseline_2); some poorperforming colleges having an efficiency score of less than 0.1 , with the best performers close to the maximum (1). 
Table 2

Production Function: Baseline Estimates

\begin{tabular}{|c|c|c|c|}
\hline Variable & Baseline_1 & Baseline_2 & $\begin{array}{l}\text { Cobb-Douglas } \\
\text { Specification }\end{array}$ \\
\hline \multirow[t]{2}{*}{$\operatorname{Ln}$ (Costs) } & $0.629 * * *$ & $0.632 * * *$ & \\
\hline & $(0.012)$ & (0.011) & \\
\hline \multirow[t]{2}{*}{ Ln(Expenditures) } & & & $0.245^{* * *}$ \\
\hline & & & (0.008) \\
\hline \multirow[t]{2}{*}{ Ln(Other Costs) } & & & $0.402 * * *$ \\
\hline & & & $(0.010)$ \\
\hline \multirow[t]{2}{*}{ Constant } & $5.038 * * *$ & $4.320 * * *$ & $4.692 * * *$ \\
\hline & $(0.063)$ & $(0.079)$ & $(0.074)$ \\
\hline State fixed effects & No & Yes & Yes \\
\hline $\mathrm{mu}$ & 0.973 & 0.067 & -0.493 \\
\hline \multirow[t]{2}{*}{ eta } & $0.008 * * *$ & $0.013^{* * *}$ & $0.014 * * *$ \\
\hline & $(0.001)$ & $(0.001)$ & (0.001) \\
\hline sigma2 & 0.372 & 0.610 & 0.749 \\
\hline sigmau2 & 0.334 & 0.572 & 0.713 \\
\hline gamma & 0.896 & 0.937 & 0.952 \\
\hline Log-likelihood & -409.6 & -187.4 & 122.8 \\
\hline Wald chi2 & 2926.6 & 8011.3 & 8808.6 \\
\hline$N$ & 7280 & 7241 & 6710 \\
\hline
\end{tabular}

Notes. IPEDS data for unbalanced panel of approximately 900 community colleges, financial years 2003-2010. BC-92 specification. Parameters: /mu is the estimated mean of the truncated normal distribution of the inefficiency term; /eta is the estimation of the change of inefficiency over time; /sigma2 is the overall variance; /sigmau2 is the variance of the inefficiency term; /gamma is the portion of overall variance (\%) explained by sigmau2. Standard errors in parentheses.

$* * * \mathrm{p}<.01$. 
Figure 1

Distribution of Technical Efficiency Scores (Academic Year 2010)

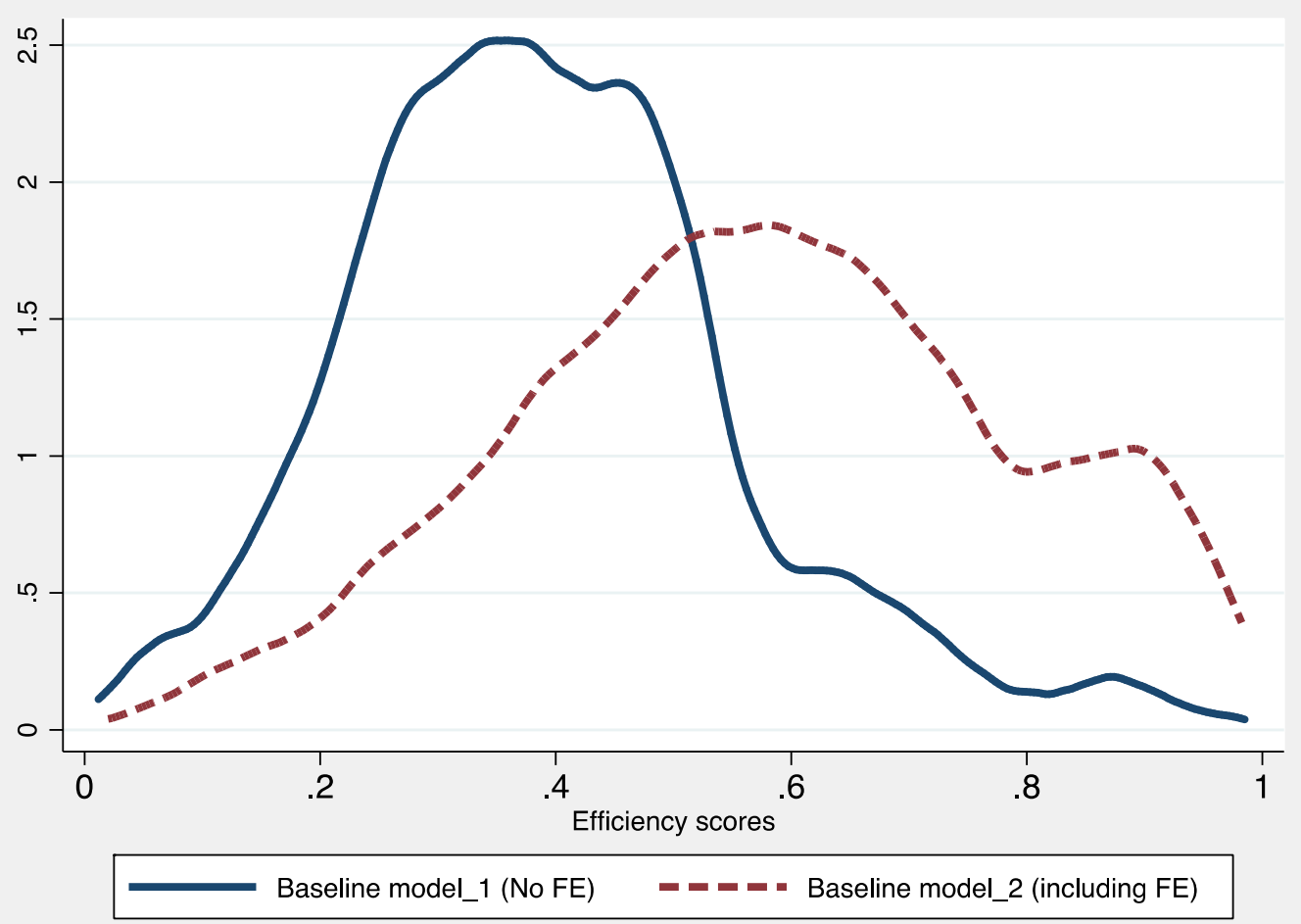

Notes: See Table 2 for specifications of baseline models. Results show Kernel density estimates.

The rightmost column in Table 2 shows results using the Cobb-Douglas specification. Coefficients of "expenditures" and "other costs" are 0.25 and 0.40 respectively; their sum is quite close to the estimated coefficient for (total) cost reported in the first two columns. Analogously, the coefficient for the constant has not changed significantly. The coefficients for the other important variables (eta, sigma2, and gamma) are very close to those for the preferred specification (as is the constant term). Efficiency scores are also highly correlated across the models $(p>0.96)$. Finally, the Cobb-Douglas results confirm the statistically significant but modest improvement in efficiency over time (mean efficiency scores increased by 4 percent over the eight year period). Given this consensus, the simplest formulation with one single input is preferred given its easier interpretation for policymaking purposes; it allows direct consideration of the impact of the overall input (current expenditures plus other costs) instead of the separate effect of 
the two components and their interaction. The advantage of dealing with a single input compensates for the strong assumptions made for this kind of production function.

\subsection{Economies of Scale}

Prior literature on four-year colleges has generally found economies of scale, with unit cost falling as output increases. As argued above, however, the technologies and inputs used by four-year institutions differ markedly from those used by community colleges.

In our analysis we find little evidence for economies of scale. A simple plot of output against total costs (not shown) indicates a broadly linear association-for example, costs appear to increase proportionately to output. Further evidence against the case for economies of scale is given in the Cobb-Douglas specification (Table 2, rightmost column): as $\beta_{1}+\beta_{2}<1$, the production process appears instead to be characterized by (low) decreasing returns to scale. Figure 2 shows the association between output and technical efficiency (estimated using Baseline_2 model in Table 2). Here, there is a moderate positive association between efficiency and output. However, the correlation is skewed by the very large colleges, few of which appear technically inefficient. Unlike the four-year sector, the case for expanding enrollments per college is not well-founded. 


\section{Figure 2}

Technical Efficiency and Output

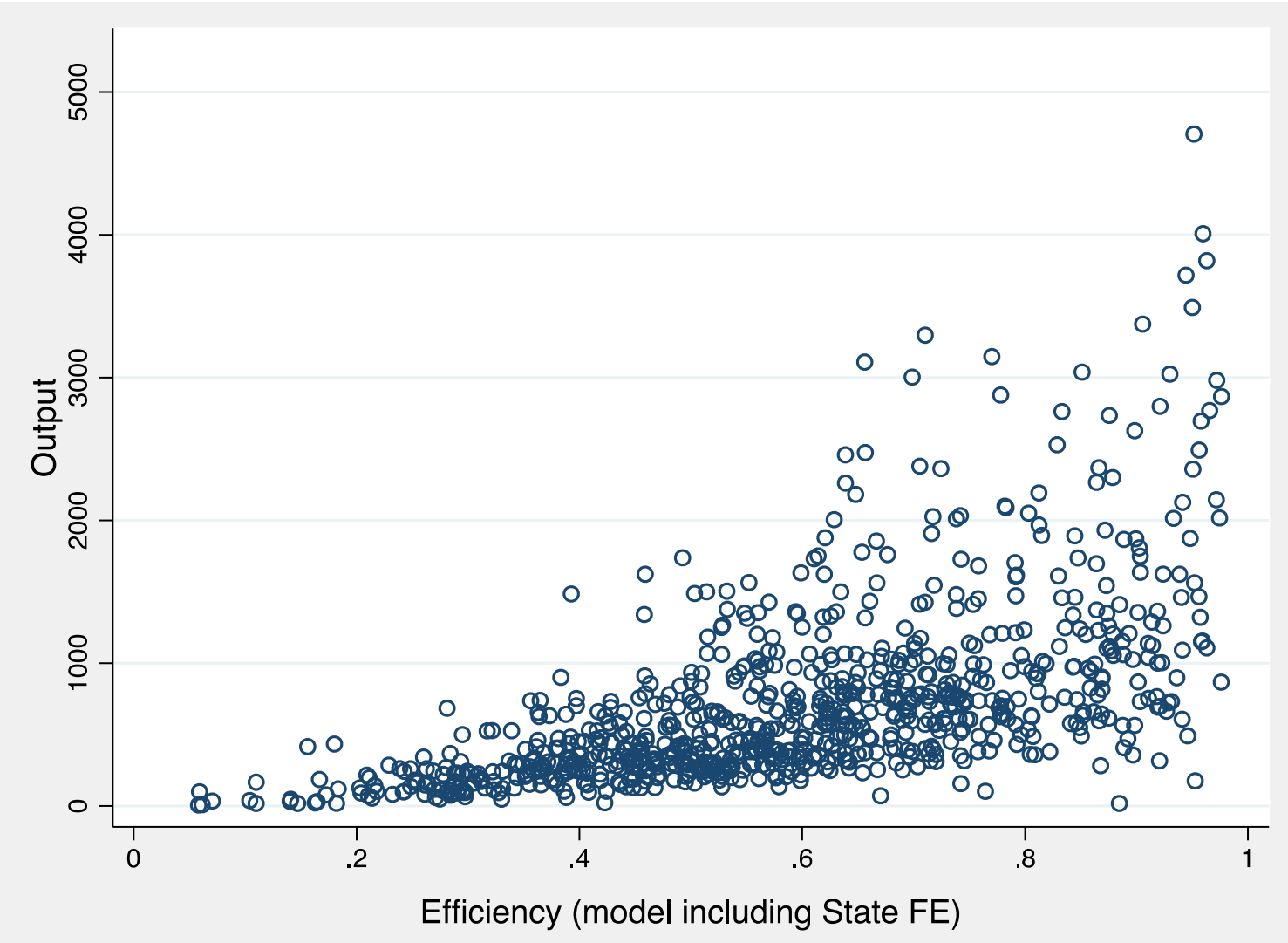

Notes: Reference year: 2010. Output is associate degree equivalents. Efficiency from the BC-92 specification with state fixed effects. Colleges with output greater than 5000 dropped (less than 1.5 percent of sample).

\subsection{External Factors Influencing Efficiency}

Table 3 shows how external factors influence efficiency, based on estimation of the equations in [5] above, using the BC-95 model. With this specification, coefficients for external factors are determining inefficiency, so positive signs indicate that colleges with these characteristics are less efficient. The production function estimates are similar to those for the baseline models. The coefficients for the external factors show that these factors have a sizeable effect on college-level efficiency. Colleges with higher proportions of minority students, which serve in these models as proxies for socioeconomic disadvantage, are less efficient. Colleges with more students aged under 25 (and more part-time students) are more efficient. These results may correspond to the ability and private sector effects found by Archibald and Feldman (2008b). Vocational 
colleges appear to be more efficient than colleges with a general academic focus, a result that is partially driven by their concentration in awarding certificates and the higher completion rates for such awards. This finding contrasts with that of Archibald and Feldman (2008b), who find a bias against "tech schools" in the four-year sector.

Table 3

Determinants of Inefficiency

\begin{tabular}{|c|c|}
\hline & Model Baseline_2 \\
\hline \multirow[t]{2}{*}{$\operatorname{Ln}(\operatorname{Cos} t)$} & $0.861 * * *$ \\
\hline & $(0.006)$ \\
\hline \multirow[t]{2}{*}{ Constant } & $-13.176 * * *$ \\
\hline & $(1.104)$ \\
\hline \multicolumn{2}{|l|}{ External factors ( $Z$ variables): } \\
\hline \multirow[t]{2}{*}{ Vocational college } & $-0.101 * *$ \\
\hline & $(0.041)$ \\
\hline \multirow[t]{2}{*}{ African American (\% students) } & $0.476 * * *$ \\
\hline & $(0.096)$ \\
\hline \multirow[t]{2}{*}{ Hispanic (\% students) } & $0.682 * * *$ \\
\hline & $(0.121)$ \\
\hline \multirow[t]{2}{*}{ Part-time (\% students) } & $-0.344 * * *$ \\
\hline & $(0.101)$ \\
\hline \multirow[t]{2}{*}{ Aged Under 25 (\% students) } & $-0.144 *$ \\
\hline & $(0.076)$ \\
\hline \multirow[t]{2}{*}{ Constant } & $1.583 * * *$ \\
\hline & $(0.107)$ \\
\hline \multirow[t]{2}{*}{ Sigma-v } & $0.249 * * *$ \\
\hline & $(0.004)$ \\
\hline Log-likelihood & -2944.6 \\
\hline Wald chi2 & 37511.1 \\
\hline $\mathrm{N}$ & 7153 \\
\hline
\end{tabular}

Notes. Specification follows BC-95. Sigma-v represents the standard deviation due to idiosyncratic error term. State fixed effects included. Standard errors in parentheses.

${ }^{*} p<.1 .{ }^{* *} p<.05 .{ }^{* * *} p<.01$. 
We then estimate a new set of efficiency scores, net of the effects of the $Z$ variables shown in Table 3. These new efficiency scores are correlated 0.715 with those from Baseline_2 (both models include state fixed effects). Figure 3 shows the two sets of efficiency scores for colleges in 2010. If external factors were unimportant, the correlation would be a 45-degree line from the origin and there would be few colleges in the upper left and lower right quadrants. Figure 3 does show a strong correlation between the two efficiency measures but also a non-trivial number of colleges with low baseline efficiency but high pure efficiency (upper left quadrant); in other words, although high, their correlation means that the "pure efficiency" scores are partially different from those obtained through the baseline model: some colleges appear inefficient only for the negative effect exerted by the composition of student body, while others seem efficient only because they serve a more advantaged population of students. For example, if college $\mathrm{a}_{1}$ obtains an efficiency score of 0.85 in the BC-92 and 0.70 in the BC-95 model, it means that when accounting for the characteristics of students, the college is relatively less efficient (in other words, it serves relatively more advantaged students, and this compositional effect was responsible for the high efficiency score in BC-92 specification). Instead, if the efficiency score of the college $\mathrm{a}_{2}$ did not change between BC-92 and BC-95 models, it means that college efficiency was driven not by the Z variables (students' characteristics) but by "pure" technical efficiency. The overall pattern shows that ranking systems that seek to identify the least efficient colleges may be less robust than those that seek to identify the most efficient colleges. 
Figure 3

Technical Efficiency Scores and "Pure Efficiency" Scores

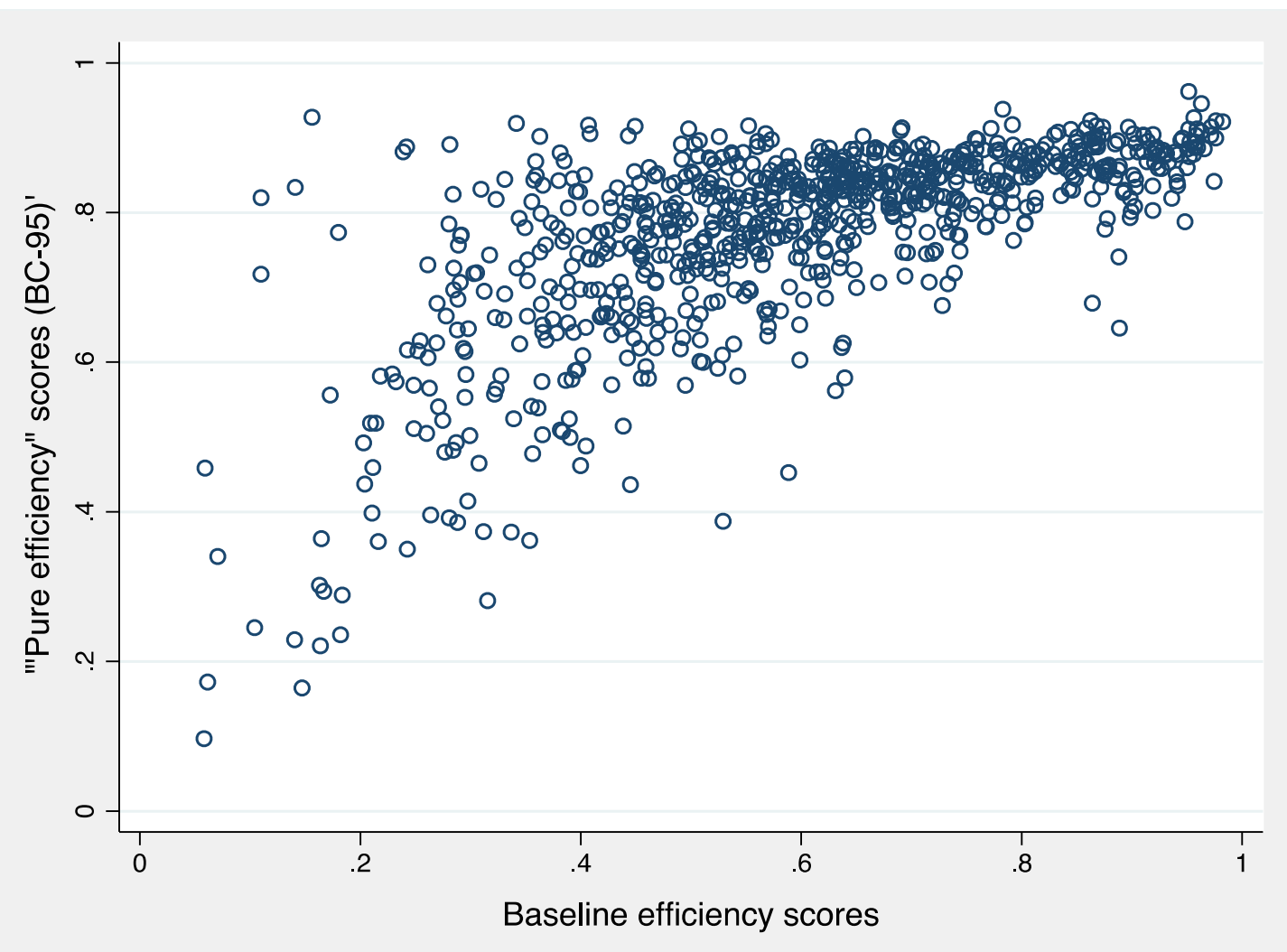

Notes: Academic year 2010. Baseline efficiency scores from Table 2 (Baseline_2 model). Pure efficiency scores from Table 3. Pairwise correlation: $0.715(p<.01)$.

\subsection{Sensitivity Testing}

Given the "black box" approach of SFA, we undertake a series of sensitivity tests on definitions of inputs/outputs. We also compare SFA with alternative approaches for estimating efficiency. For each sensitivity test, we correlate the efficiency scores against our preferred specification (Baseline_2 of Table 2).

First, we estimate the frontier using alternative measures of output. One measure is the count of those students who graduated within 150 percent of expected time. This measure is often used as a way to evaluate colleges because it is directly available from IPEDS, although it is inaccurate because many community college students work intensively while studying part-time. ${ }^{6}$ A second measure is the count of associate degrees

\footnotetext{
${ }^{6}$ This measure has other drawbacks. Very high proportions of students who start college intend to (or expect to) complete their program; their failure to do so is not accurately counted. Also, many students
} 
awarded by the colleges. This measure has been used in other studies but is inaccurate in that certificates are not included. The third measure is that proposed by the National Research Council (NRC, 2012) and described by Massy (2011): all credits are counted, but those of students who graduate are weighted more heavily (to account for the "sheepskin" value effect). The main concern with this measure is that it yields an output measure that is almost equivalent to expenditure per FTE.

We re-estimate the Baseline_2 model and the BC-95 specification from Table 2 using the three alternative measures of output (details available from the authors; also see Appendix figures and table). For all three measures, there is a clear but modest trend of increasing efficiency as for the preferred specifications. All estimations show a strong association between output and costs with elasticity between $0.4-0.7$. The technical efficiency estimates are strongly positively correlated with technical efficiency from the Baseline_2 model (with correlations of 0.35-0.64). However, there are sizable numbers of colleges ranked as relatively efficient in the Baseline_2 model but relatively inefficient when using the alternative measures of output. As well as being imprecise, these alternatives give inconsistent results for the external factors. The FTE/credit model predicts that colleges with more disadvantaged student bodies are more efficient, which seems to lack credibility. Also, when output is measured in terms of FTE per credits (Massy, 2011) or associate degrees, vocational colleges appear relatively inefficient and by very large magnitudes. Finally, the graduation rate measure identifies very large effects of student characteristics on efficiency levels; substantively, these effects appear implausible. Hence, these alternative measures do not appear to be improvements over our preferred specifications.

Second, we compare efficiency scores from SFA with two alternative measures of efficiency given in Belfield (2012) and Archibald and Feldman (2008b). Belfield (2012) calculated efficiency for community colleges using a basic measure of average social cost (cost/output), and these cost measures and output (associate degree equivalents) are very similar to ours even as no adjustment is made for colleges being on

accumulate surplus credits beyond the formal course requirements. Using a credit accumulation measure favors colleges that overload students with surplus credits. Fundamentally, an annual credit-based measure of output yields an efficiency measure which is almost equivalent to expenditure per FTE. Given low completion rates, enrollment-driven output measures are inappropriate measures of efficiency. 
the frontier. Archibald and Feldman (2008b) used the residuals from an OLS estimation of the production function as an additional alternative to the use of frontier methods. These residuals capture all unexplained variation: negative residuals imply that the college is producing less than predicted given its resources (and vice versa), and this shortfall may reflect inefficiency. In this respect, the SFA approach is better suited: it explicitly assumes that deviations from the frontier are caused by inefficiency and not random noise, whereas OLS residuals are comprised of both random fluctuations and inefficiency.

Appendix Figure A.1 shows the correlations between our preferred specification and that of Belfield (2012) for community colleges in 2010. There is a clear negative correlation: technically efficient colleges are those with lower average cost per degree. Thus, the two methods provide efficiency judgments that are quantitatively similar (pairwise correlation of $0.461, p<0.01$ ). As well, Appendix Figure A.2 shows a clear association between technical efficiency scores and OLS residuals, the latter calculated in the manner of Archibald and Feldman (2008b). These methods yield rankings that are very similar across colleges (pairwise correlation of $0.793, p<0.01$ ). ${ }^{7}$ Given its greater predictive power for inefficiency below the frontier, the SFA approach is therefore preferred.

Third, we correlate our efficiency scores (BC-95) with other student characteristics that might influence efficiency. One factor is college location. Urban colleges might be expected to have students with weaker college readiness because of lower school quality (and to have higher costs because wages for educated workers are relatively higher). Also, colleges with higher proportions of remedial students may be less efficient: not only are these students less well-prepared for college but they must take additional courses which do not count for credit toward an award. ${ }^{8}$ Unfortunately, urbanicity and remediation rates are not included in our national datasets and have to be identified from state-level databases. Few states report this information in a consistent

\footnotetext{
${ }^{7}$ In their estimation across public institutions, Archibald and Feldman (2008b) found similar results using the OLS residuals and those from SFA.

${ }^{8}$ Nationally, approximately two-thirds of entering community college students must take at least one remedial course and many take several; less than half of these students complete their remediation sequence, and only one-third of students who take a remedial course ever earn any postsecondary credential (Bailey, Jeong, \& Cho, 2010).
} 
way, so the sample for analysis is substantially smaller than our main analysis. Therefore, we are only able to report correlations between our efficiency measures for a subsample of colleges. For this subsample, looking across all years and all colleges, the association between urban setting and college efficiency is positive (pairwise correlation $=0.07, p \leq$ .1). By contrast, college efficiency varies inversely with the remediation rate (defined as the proportion of first-time-in-college students who must take remediation). However, the association is based only on 176 colleges across seven states and lacks statistical power (pairwise correlation $=-0.09, p=.26$ ). Differences in remediation may therefore be an important influence on efficiency, although the limited data make it hard to test this hypothesis.

\section{Policy Implications}

One disadvantage of frontier analysis (and regression analysis generally) is that the method sometimes appears opaque, and the results are not easily intelligible to policymakers. Here, we show how SFA can be applied in a policy context. Specifically, we focus on two key elements of current policy: the need to offset the supposed deterioration in efficiency over time across the sector, and the imperative to create rankings for colleges so that students can make more informed enrollment choices and so that policymakers can tie resources to outcomes (on performance funding and efficiency calculations, see Sexton, Comunale, \& Gara, 2012).

\subsection{Trends in Efficiency Over Time}

One motivation for increased policy intervention in the community college system is the belief that colleges are becoming less efficient over time. The low graduation rates of students at community colleges has been identified as prima facie evidence that they are probably not allocating resources efficiently and certainly not becoming more efficient over time. However, community colleges have experienced significant reductions in state funding: measured in constant dollars, state appropriations per fulltime equivalent student were 25 percent lower in 2009 than in 1999 (Snyder \& Dillow, 
2012). On this logic, if colleges had maintained the same operations, output should have also fallen by a corresponding amount. Given these trends in funding, it is critical to establish whether colleges are becoming more or less efficient over time.

Our SFA specifications indicate trends in efficiency across the sector (applying a consistent model specification over time should also reduce measurement error bias). The Baseline_2 model in Tables 2 and 3 shows that community college efficiency is trending upward (eta $>0, p<0.01$ ). The trend is substantively small but consistent across almost all years. To illustrate, Table 4 shows efficiency scores disaggregated by year (using the Baseline_2 model from Table 2). Efficiency increases slightly each year (with the exception of 2006). The average annual growth rate is less than one percent such that the cumulative efficiency gain over the period 2003-2010 is a modest 5.3 percent (results are similar when using the BC-95 model). Across all specifications there is no evidence that colleges are becoming less efficient over time. This result differs from that found by Harris and Goldrick-Rab (2010), who reported declining productivity over time among community colleges. Their output measure does not, however, include certificates, and their model is not adjusted for covariates. But our findings are consistent with DesRochers and Hurlburt (2012, Figure 2), who estimated average production costs (for degrees and certificates combined) that are 14 percent lower in 2010 than in 2000.

Table 4

Efficiency Scores Over Time

\begin{tabular}{lccc}
\hline & $\begin{array}{c}\text { Efficiency Scores } \\
\text { (Baseline_1) }\end{array}$ & $\begin{array}{c}\text { Efficiency Scores } \\
\text { (Baseline_2) }\end{array}$ & $\begin{array}{c}\text { Annual Percentage } \\
\text { Increase (Baseline_2) }\end{array}$ \\
\hline $\mathbf{2 0 0 3}$ & 0.384 & & - \\
$\mathbf{2 0 0 4}$ & 0.387 & 0.564 & $0.69 \%$ \\
$\mathbf{2 0 0 5}$ & 0.391 & 0.568 & $0.82 \%$ \\
$\mathbf{2 0 0 6}$ & 0.389 & 0.573 & $-0.09 \%$ \\
$\mathbf{2 0 0 7}$ & 0.393 & 0.572 & $0.78 \%$ \\
$\mathbf{2 0 0 8}$ & 0.399 & 0.577 & $2.11 \%$ \\
$\mathbf{2 0 0 9}$ & 0.400 & 0.589 & $0.50 \%$ \\
$\mathbf{2 0 1 0}$ & 0.400 & 0.592 & $0.42 \%$ \\
& & 0.594 & \\
Mean (all years) & 0.393 & & $0.75 \%$
\end{tabular}


This general increase in efficiency is spread across the sector. It is not driven by greater gains at more efficient colleges relative to slower gains (or declines) at less efficient colleges. Looking at college-level trends, the sector is not polarizing into highly efficient and inefficient colleges. Instead, all colleges across the sector are making modest variable gains from different starting levels of efficiency.

Finally, these efficiency gains over time are measured from a social perspective; when considered from a fiscal perspective, the gains are even greater. With declining public support for colleges and higher tuition, the taxpayer accrues a greater share of any efficiency gains. Indeed, Belfield (2012, Table 2) estimated that fiscal average cost fell by 22-33 percent at academic and vocational community colleges between 2001 and 2008 , i.e., by a much greater amount than the gain in social efficiency. To test this, we estimate the BC-95 model using only costs incurred by the colleges (net of tuition). We find efficiency growth over the period 2003-10 of comparable magnitude to that using social cost (details available from the authors). Overall, there is no evidence of a general decline in efficiency across the community college sector.

\subsection{Ranking Colleges and Resource Implications}

Another policy trend is a move to develop rankings of colleges such that highperforming colleges can be identified. Sector-wide efficiency gains may be generated if colleges can emulate best practices at the most efficient colleges. However, for this approach to have validity it is necessary for the most efficient colleges to be identifiable.

SFA does allow colleges to be ranked, and these rankings may be an improvement over alternative ranking methods. As a check, we compare the rankings our efficiency scores imply with other ranking metrics for the most recent year of data available (2010). At present, there are no national rankings for community colleges similar to those for four-year institutions such as the U.S. News \& World Report rankings. So, we create a ranking similar to the method used for U.S. News \& World Report rankings. This ranking is based on a weighted valuation of each college's graduation rate, retention rate, and student-faculty ratio. Also, we look at rankings based on student "return on investment (ROI)" (Klor de Alva \& Schneider, 2013), i.e., what gain in earnings are predicted for each college. The correlation between these ranking systems and our preferred measure 
of efficiency is close to zero. ${ }^{9}$ We therefore caution that simple ranking systems may be misleading guides to efficiency both for policymakers and students.

What is more, there are other challenges in using efficiency scores as rankings on which to make enrollment and resource allocation decisions. First, as shown in Figure 2, many colleges have efficiency levels that are close to the frontier. Lower rankings are therefore unlikely to connote significantly lower efficiency levels. Second, the rankings need to be stable over time such that colleges identified as the most efficient in one year are also the most efficient in subsequent years. Correlations between rankings are high across years and across the community college sector nationally, but most significant institutional policy decisions are made at the state-level. Thus, rankings need to be stable over time within states and must identify consistently efficient colleges over time.

To test for stability in rankings within states, we list identify the ten most efficient colleges in 2003, 2006, and 2010 in two states: California and Texas. In California, only three colleges are ranking in the top ten for all of the three years. In Texas, no college is ranked in the top ten most efficient community colleges in all three years. This instability reflects two empirical features. First, few colleges stand out as consistently more efficient than the average. Second, small changes in efficiency year-on-year are influential on ordinal rankings within states. Overall, the results from SFA to generate ordinal efficiency rankings should be cautiously applied.

\section{Conclusions}

Recent policy developments, with an emphasis on cost-cutting and college rankings, have increased the focus on identifying efficiency. Yet, defining efficiency is not a straightforward concept in higher education, so several alternative approaches may be appropriate. In addition to basic measures of average cost or cost per FTE, more technical approaches should be applied. Indeed, given its market structure, student

\footnotetext{
${ }^{9}$ For the student ROI rankings, pairwise correlations are 0.005 (Baseline_2) and -0.09 (BC-95). For the U.S. News \& World Report approximation the pairwise correlations are -0.06 and 0.03 , respectively. Correlations are for 523 colleges with efficiency scores in 2010.
} 
enrollment patterns, and institutional characteristics, the community college sector is highly suited to application of stochastic frontier analysis.

Our SFA results show several important results. First, an increase of one percent in costs is associated with an increase of 0.6 percent in output. Second, there is considerable heterogeneity across states - adjusting for state-specific constraints is therefore important. Third, students characteristics do matter, although they do not have a strong influence on the overall elasticity of costs with respect to output. Fourth, SFA is preferred to alternative methods for estimating efficiency. As well as modeling efficiency with respect to the most efficient colleges, SFA results yield plausible associations between student characteristics and efficiency - a finding that stands in contrast to alternative models for estimating efficiency. Fifth, in two respects the results for community colleges contrast to results across the higher education sector in the U.S. One is that community colleges do not appear to exhibit significant economies of scale; as colleges increase in size, the variation in efficiency increases. The other is that these colleges have become more efficient over the decade of the 2000s; output has not fallen as fast as revenues. Finally, we caution that rankings based on SFA — and other measures of efficiency - may be very sensitive either to small modeling perturbations or to the year in which efficiency is being identified.

Our analysis has focused on technical efficiency within the community college sector and distinguished efficient from inefficient colleges. However, as a final note we emphasize the other sense of efficiency, i.e., whether the sector produces enough output as a whole to meet the needs of the economy. In this sense, economic evidence strongly suggests that output is too low: the economic value of community college easily exceeds the cost (Belfield \& Bailey, 2011). Thus, even as colleges vary with respect to efficiency, suggesting that resources should be reallocated to the more efficient colleges, there is an economic rationale for expanding provision across the sector. 


\section{References}

Agasisti, T., \& Bonomi, F. (2013). Benchmarking universities' efficiency indicators in the presence of internal heterogeneity. Studies in Higher Education, 1-19.

Agasisti, T., \& Johnes, G. (2010). Heterogeneity and the evaluation of efficiency: The case of Italian universities. Applied Economics, 42(11), 1365-1375.

Aigner, D., Lovell, C. K. \& Schmidt, P. (1977). Formulation and estimation of stochastic frontier production function models. Journal of Econometrics, 6, 21-37.

Archibald, R. B., \& Feldman, D. H. (2008a). Explaining increases in higher education costs. Journal of Higher Education, 79, 268-295.

Archibald, R.B. and D.H. Feldman. 2008b. Graduation rates and accountability: Regressions versus production frontiers. Research in Higher Education, 49, 80100 .

Bailey, T. (2012). Can community colleges achieve ambitious graduation goals? In A. P. Kelly \& M. Schneider (Eds.), Getting to graduation: The completion agenda in higher education (pp. 73-101). Baltimore, MD: Johns Hopkins University Press.

Bailey, T., Jeong, D. W., \& Cho, S. W. (2010). Referral, enrollment, and completion in developmental education sequences in community colleges. Economics of Education Review, 29(2), 255-270.

Battese, G.E. \& T.J. Coelli. (1992). Frontier production functions, technical efficiency and panel data. Journal of Productivity Analysis, 3, 153-169.

Battese, G.E. \& T.J. Coelli. (1995). A model for technical inefficiency effects in a stochastic frontier production function for panel data. Empirical Economics, 20, $325-332$

Belfield, C.R. (2012). Measuring efficiency in the community college sector. CCRC Working Paper, http://ccrc.tc.columbia.edu/publications/measuring-efficiencycommunity-college-sector.html.

Belfield, C. R., \& Bailey, T. (2011). The benefits of attending community college: A review of the evidence. Community College Review, 39(1), 46-68.

Belfield, C. R., Crosta, P., \& Jenkins, D. (2013). Can community colleges afford to improve completion? Measuring the costs and efficiency effects of recent reforms (CCRC Working Paper No. 55). New York, NY: Columbia University, Teachers College, Community College Research Center.

Bound, J., Lovenheim, M. F., \& Turner, S. (2010). Why have college completion rates declined? An analysis of changing student preparation and collegiate resources. American Economic Journal: Applied Economics, 2(3), 129-157. 
Bowen, H. R. (1980). The costs of higher education: How much do colleges and universities spend per student and how much should they spend? San Francisco, CA: Jossey-Bass.

Clotfelter, C. T., Ladd, H. F., Muschkin, C. G., \& Vigdor, J. L. (2013). Success in community college: Do institutions differ? Research in Higher Education, 54(7), 805-824. doi:10.1007/s11162-013-9295-6

Cohn, E., Rhine, S. L. W., \& Santos, M. C. (1989). Institutions of higher education as multi-product firms: Economies of scale and scope. Review of Economics and Statistics, 71(2), 284-290.

de Groot, H., McMahon, W. W., \& Volkwein, J. F. (1991). The cost structure of American research universities. Review of Economics and Statistics, 73(3), 424431.

Desrochers, D. M., \& Wellman, J. V. (2011). Trends in college spending 1999-2009. Washington, DC: Delta Cost Project. Retrieved from http://www.deltacostproject.org/resources/pdf/Trends2011_Final 090711.pdf

Desrochers, D. M., \& Hurlburt, S. (2012). Spending and results: What does the money buy? A Delta data update: 2000-2010. Washington, DC: Delta Cost Project. Retrieved from http://www.deltacostproject.org/resources/pdf/Delta-Cost-TrendsOutcomes.pdf

Dolan, R., \& Schmidt, R. (1994). Modeling institutional production of higher education. Economics of Education Review, 13(3), 197-213.

Harris, D., \& Goldrick-Rab, S. (2010). The (un)productivity of American higher education (WISCAPE Working Paper). Madison, WI: University of WisconsinMadison, Wisconsin Center for the Advancement of Postsecondary Education.,

Harter, J. F. R., Wade, J. A., \& Watkins, T. G. (2005). An examination of costs at fouryear public colleges and universities between 1989 and 1998. The Review of Higher Education, 28(3), 369-391.

Hashimoto, K., \& Cohn, E. (1997). Economies of scale and scope in Japanese private universities. Education Economics, 5(2), 107-116.

Horn, L., Li, X., \&Weko, T. (2009). Changes in postsecondary awards below the bachelor's degree: 1997 to 2007 (NCES 2010-167). Washington, DC: U.S. Department of Education, Institute of Education Sciences, National Center for Education Statistics. 
Hossler, D., Shapiro, D., Dundar, A., Ziskin, M., Chen, J., Zerquera, D., \& Torres, V.. (2012). Transfer and mobility: A national view of pre-degree student movement in postsecondary institutions. Herndon, VA: National Student Clearinghouse Research Center. Retrieved from http://www.nscresearchcenter.org/signaturereport2

Jenkins, D., \& Rodriguez, O. (2013). Access and success with less: Improving productivity in broad-access postsecondary institutions. The Future of Children, 23(1), 187-209.

Johnes, J. 2006. Data envelopment analysis and its application to the measurement of efficiency in higher education. Economics of Education Review, 25(3), 273-288.

Johnes, J. 2008. Efficiency and productivity change in the English higher education sector from 1996/97 to 2004/5. Manchester School, 76, 653-674.

Kempkes, G., \& Pohl, C. (2010). The efficiency of German universities-Some evidence from nonparametric and parametric methods. Applied Economics, 42(16), 20632079.

Klor de Alva, J., \& Schneider, M. (2013). What's the value of an associate's degree? The return on investment for graduates and taxpayers. Washington, DC: American Institutes for Research and Nexus Research and Policy Center.

Kumbhakar, S. C., \& Lovell, C. A. (2000). Stochastic frontier analysis. Cambridge, UK: Cambridge University Press.

Laband, D. N., \& Lentz, B. F. (2004). Do costs differ between for-profit and not-forprofit producers of higher education? Research in Higher Education, 45(4), 429441.

Massy, W. F. (2011). Metrics for efficiency and effectiveness in higher education. Washington DC: National Governors Association, The Miller Center on Public Affairs.

Medwick, A. J. (2009). Transfer-out reporting on the IPEDS graduation rate survey: A first look at trends and methods (An AIR/NCES Data Policy Fellowship Report). Washington, DC: U.S. Department of Education, Institute for Education Sciences, National Center for Education Statistics.

National Research Council (NRC) (2012). Improving Measurement of Productivity in Higher Education. Sullivan, T.A., Mackie, C., Massy, W. F., and E. Sinha (Eds). Committee on National Statistics and Board on Testing and Assessment, Division of Behavioral and Social Sciences and Education. Washington, DC: The National Academies Press. 
Powell, B. A., Gilleland, D. S., \& Pearson, L. C. (2012). Expenditures, efficiency, and effectiveness in U.S. undergraduate higher education: A national benchmark model. Journal of Higher Education, 83(1), 102-127.

Sexton, T. R., Comunale, C. L., \& Gara, S. C. (2012). Efficiency-based funding for public four-year colleges and universities. Education Finance and Policy, 7(3), $331-359$.

Snyder, T. D., \& Dillow, S. A. (2012). Digest of education statistics 2011 (NCES 2012001). Washington, DC: U.S. Department of Education, Institute of Education Sciences, National Center for Education Statistics.

Stange, K. (2012). Ability sorting and the importance of college quality to student achievement: Evidence from community colleges. Education Finance and Policy, 7(1), 74-105.

The White House, Office of the Press Secretary. (2013). Fact sheet on the President's plan to make college more affordable: A better bargain for the middle class [Press release]. Retrieved from http://www.whitehouse.gov/the-pressoffice/2013/08/22/fact-sheet-president-s-plan-make-college-more-affordablebetter-bargain-

Trostel, P. (2010). The fiscal impacts of college attainment. Research in Higher Education, 51(3), 220-247.

Webber, D. A., \& Ehrenberg, R. G. (2010). Do expenditures other than instructional expenditures affect graduation and persistence rates in American higher education? Economics of Education Review, 29(6), 947-958.

Winston, G. C. (1999). Subsidies, hierarchy and peers: The awkward economics of higher education. Journal of Economic Perspectives, 13(1), 13-36.

Zhang, L. (2009). Does state funding affect graduation rates at public four-year colleges and universities? Educational Policy, 23(5), 714-731. 


\section{Appendix}

\section{Appendix Figure A.1 \\ Technical Efficiency Scores and Unit Cost per Degree-Equivalent}

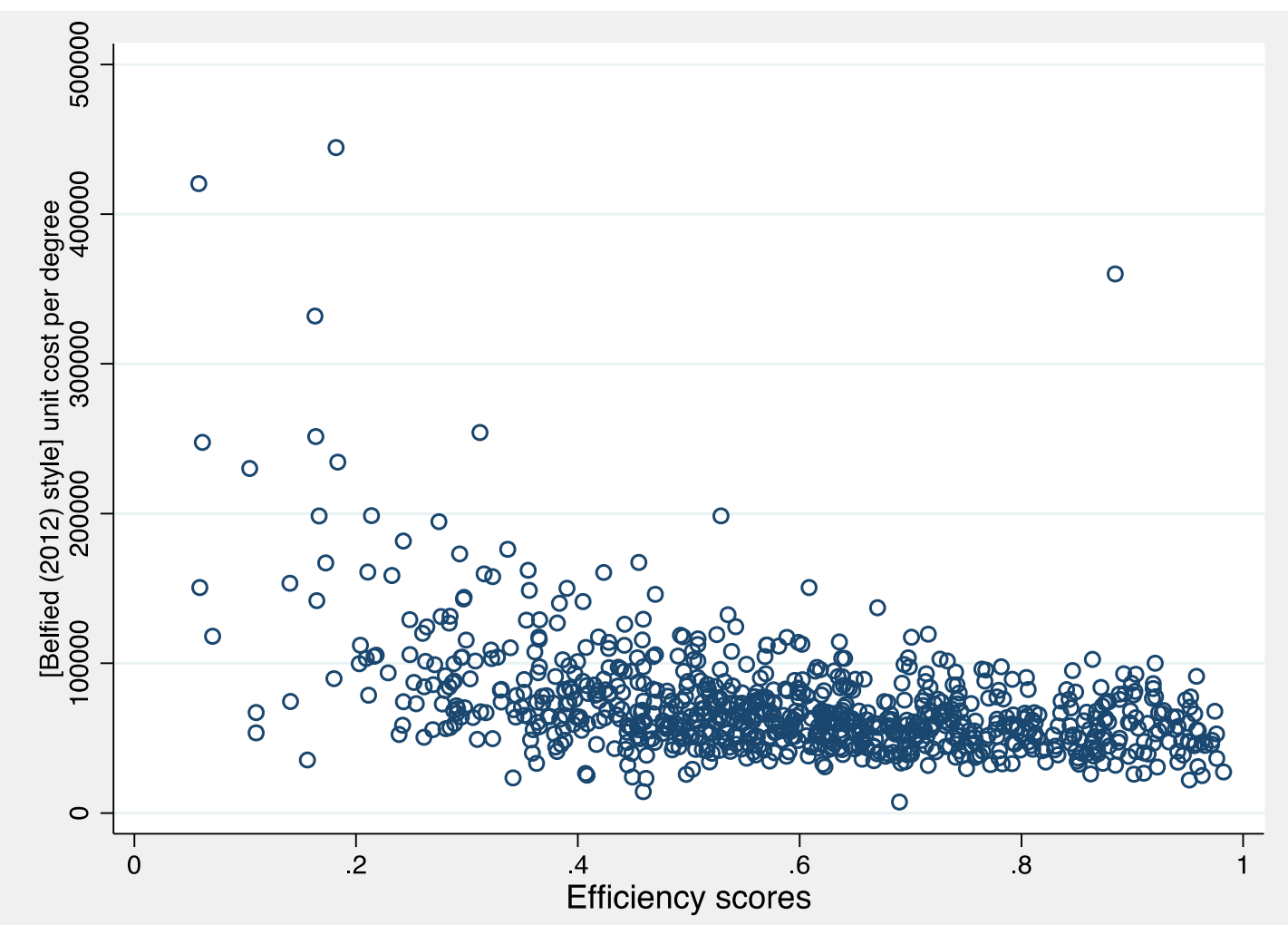

Notes. Academic year 2010. Efficiency scores from Table 2 (Baseline_2 model). Unit-cost per degreeequivalent from Belfield (2012). 


\section{Appendix Figure A.2 \\ Technical Efficiency Scores and OLS Residuals}

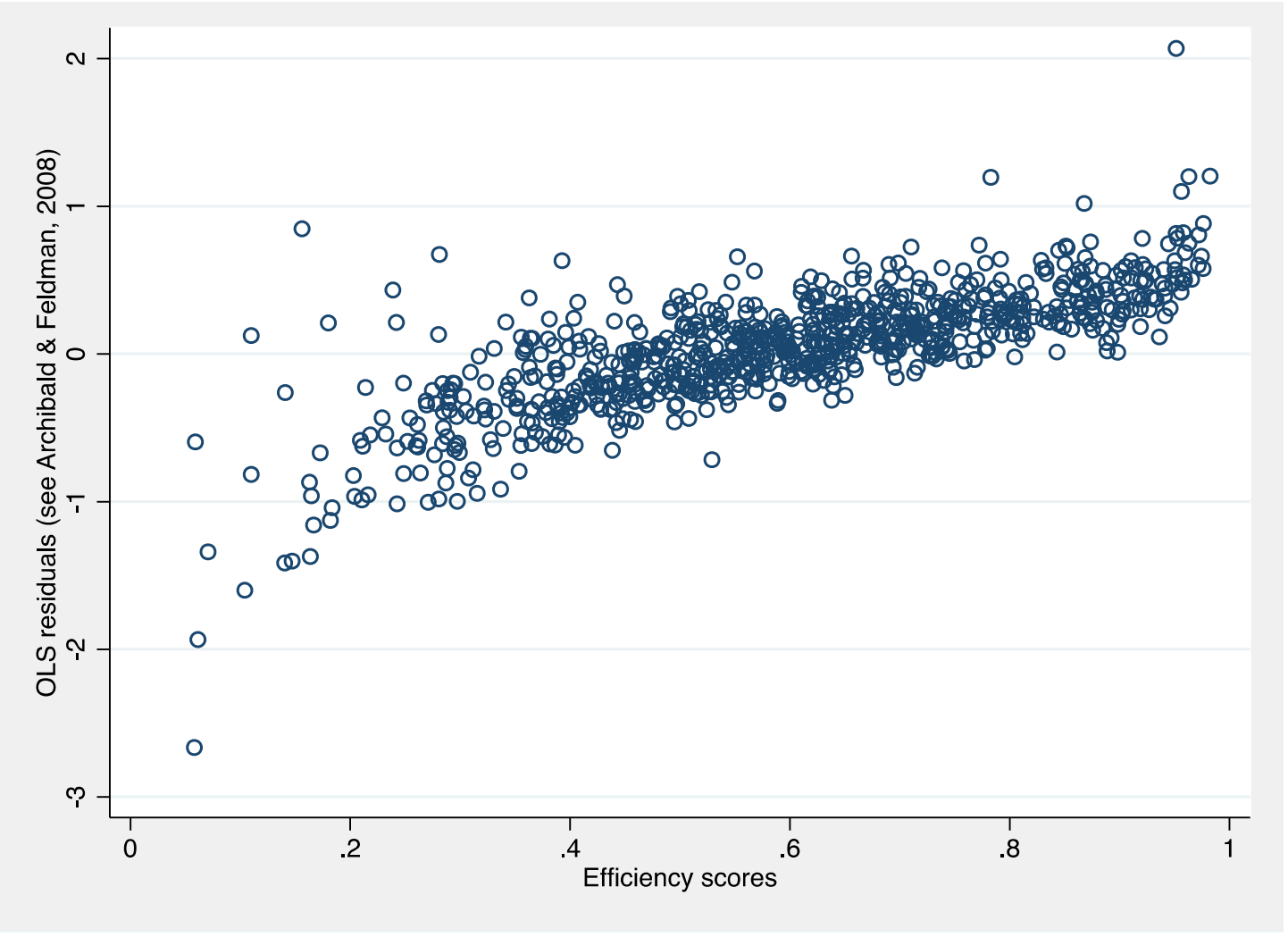

Notes. Academic year 2010. Efficiency scores from Table 2 (Baseline_2 model). OLS residuals from log$\log$ model of output regressed against cost as per the SFA specifications with error terms assumed normally distributed. 
Appendix Table A.1

Sensitivity Tests: Alternative Measures of Output

\begin{tabular}{|c|c|c|c|c|}
\hline & Baseline & FTE/credits output & AA degrees & Grad150 Count \\
\hline \multirow[t]{2}{*}{$\operatorname{Ln}($ Cost $)$} & $0.861 * * *$ & $1.006^{* * *}$ & $0.980 * * *$ & $0.572 * * *$ \\
\hline & 156.04 & 238.01 & 161.67 & 56.89 \\
\hline \multirow[t]{2}{*}{ Constant } & $3.317^{* * *}$ & $4.573 * * *$ & $2.740 * * *$ & $2.940 * * *$ \\
\hline & 106.72 & 182.30 & 84.14 & 51.31 \\
\hline \multicolumn{5}{|l|}{ External variables (Z) } \\
\hline \multirow[t]{2}{*}{ Vocational college } & $-0.101^{*}$ & $0.941 * * *$ & $1.024^{* * *}$ & $-0.396 * * *$ \\
\hline & -2.45 & 19.72 & 20.62 & -97.05 \\
\hline \multirow[t]{2}{*}{ African American (\% students) } & $0.476 * * *$ & -0.021 & $1.054^{* * *}$ & $3.252^{* * *}$ \\
\hline & 4.98 & -0.18 & 10.64 & 228.56 \\
\hline \multirow[t]{2}{*}{ Hispanic (\% students) } & $0.682 * * *$ & $1.515^{* * *}$ & $0.921 * * *$ & 2.027 \\
\hline & 5.65 & 10.10 & 6.70 & n.d. \\
\hline \multirow[t]{2}{*}{ Part-time (\% students) } & $-0.344 * * *$ & $-0.701 * * *$ & 0.072 & $5.868^{* * *}$ \\
\hline & -3.42 & -6.69 & 0.66 & 527.69 \\
\hline \multirow[t]{2}{*}{ Aged Under 25 (\% students) } & -0.144 & -0.064 & $-0.565^{* * *}$ & 1.853 \\
\hline & -1.90 & -0.73 & -6.57 & n.d. \\
\hline \multirow[t]{2}{*}{ Constant } & $1.583^{* * *}$ & $-0.794 * * *$ & $0.393^{*}$ & $-5.202 * * *$ \\
\hline & 14.81 & -8.24 & 2.10 & -1407.12 \\
\hline \multirow[t]{2}{*}{ V Sigma } & $-2.784 * * *$ & $-3.242 * * *$ & $-2.976 * * *$ & -0.915 \\
\hline & -83.22 & -101.50 & -76.88 & n.d. \\
\hline$N$ & 7153 & 7153 & 6767 & 7239 \\
\hline
\end{tabular}

Notes. V-sigma represents the standard deviation due to the idiosyncratic error term. State fixed effects included. ${ }^{*} p<.1 .{ }^{*} p<.05 .{ }^{* * *} p<.01$. 